\title{
Ischemic stroke, hemorrhage, and mortality in patients with non-valvular atrial fibrillation and renal dysfunction treated with rivaroxaban: sub-analysis of the EXPAND study
}

\author{
Hirotsugu Atarashi ${ }^{1}$. Shinichiro Uchiyama ${ }^{2} \cdot$ Hiroshi Inoue $^{3} \cdot$ Takanari Kitazono $^{4} \cdot$ Takeshi Yamashita $^{5}$. \\ Wataru Shimizu $^{6} \cdot$ Takanori Ikeda $^{7} \cdot$ Masahiro Kamouchi $^{8} \cdot$ Koichi Kaikita $^{9} \cdot$ Koji Fukuda $^{10} \cdot$ Hideki Origasa $^{11}$. \\ Hiroaki Shimokawa ${ }^{12,13}$ (ID)
}

Received: 8 September 2020 / Accepted: 19 February 2021 / Published online: 16 March 2021

(c) The Author(s) 2021

\begin{abstract}
The EXPAND Study demonstrated the effectiveness and safety of rivaroxaban in patients with non-valvular atrial fibrillation (NVAF) in routine clinical practice in Japan. This sub-analysis was conducted to reveal the effectiveness and safety of rivaroxaban in Japanese NVAF patients according to baseline creatinine clearance $(\mathrm{CrCl})$ levels and rivaroxaban doses in the EXPAND Study. We examined 6806 patients whose baseline $\mathrm{CrCl}$ data were available and classified them into 2 groups: normal renal function group with $\mathrm{CrCl} \geq 50 \mathrm{~mL} / \mathrm{min}(n=5326,78 \%)$ and renal dysfunction group with $\mathrm{CrCl}<50 \mathrm{~mL} / \mathrm{min}$ $(n=1480,22 \%)$. In the normal renal function group, 1609 (30\%) received $10 \mathrm{mg} /$ day (under-dose), while in the renal dysfunction group, 108 (7\%) received $15 \mathrm{mg}$ /day (over-dose). In the normal renal function group, under-dose of rivaroxaban was associated with higher all-cause mortality, while in the renal dysfunction group, over-dose was associated with higher incidence of major bleeding. In contrast, the incidence of stroke or systemic embolism was not different between the 2 groups regardless of the dose of rivaroxaban. In the propensity score matched analysis to adjust the difference in characteristics according to doses of rivaroxaban, the incidences of clinical outcomes were comparable between the 2 dose groups in both renal function groups. These results indicate that the dose of rivaroxaban should be reduced depending on the renal function, considering the balance between risks of bleeding and ischemia.
\end{abstract}

Keywords Non-valvular atrial fibrillation $\cdot$ Rivaroxaban $\cdot$ Renal dysfunction $\cdot$ Creatinine clearance

$\begin{array}{ll}\text { Abbreviations } \\ \mathrm{AF} & \text { Atrial fibrillation } \\ \mathrm{CrCl} & \text { Creatinine clearance } \\ \text { DOACs } & \text { Direct oral anticoagulants } \\ \text { NVAF } & \text { Non-valvular atrial fibrillation } \\ \mathrm{PSM} & \text { Propensity score matching } \\ \mathrm{SD} & \text { Standard deviation } \\ \mathrm{SE} & \text { Systemic embolism }\end{array}$

Hiroaki Shimokawa

shimo@cardio.med.tohoku.ac.jp

Extended author information available on the last page of the article

\section{Introduction}

Atrial fibrillation (AF) is a most commonly encountered arrhythmia in routine clinical practice and is widely known as a risk factor for not only stroke and systemic embolism (SE) but also dementia [1, 2]. In Japan, the morbidity of AF has been increasing along with rapid aging of the society [3]. Direct oral anticoagulants (DOACs) are widely used for the prevention of stroke/SE in patients with non-valvular atrial fibrillation (NVAF); however, they require dose adjustment according to renal function and are thus contraindicated in patients with severe renal dysfunction $[4,5]$. In addition, aggravation of renal function with aging has been reported as in the case of glucose tolerance and lipid metabolism [6].

Renal dysfunction is an independent risk factor for ischemic stroke, and the risks of stroke and all-cause death are increased in patients with AF [7-13]. A previous meta-analysis reported that warfarin decreased the risk of ischemic stroke/SE and all-cause mortality in patients 
with non-end stage chronic kidney disease [14]. In addition, a relationship between renal dysfunction and clinical outcomes in Japanese patients with AF has been examined in the Fushimi AF Registry and the J-RHYTHM Registry [15, 16]; however, the evidence in patients treated with DOACs remains to be accumulated more.

The safety and efficacy of rivaroxaban, one of DOACs, were evaluated as compared with dose-adjusted warfarin in the previous clinical trials (ROCKET AF and J-ROCKET $\mathrm{AF}$ trials) $[17,18]$. In the global ROCKET AF trial, rivaroxaban was administered at a dose of $20 \mathrm{mg} /$ day and $15 \mathrm{mg} / \mathrm{day}$ to patients with normal renal function and those with renal dysfunction with a creatinine clearance $(\mathrm{CrCl}) \leq 50 \mathrm{mg} / \mathrm{min}$, respectively. The results showed no interaction between the study doses regardless of the state of renal function $[17,19]$. In the J-ROCKET AF trial in Japan, which was conducted to examine the safety and efficacy of rivaroxaban at doses adjusted for Japanese patients, rivaroxaban was administered at a dose of $15 \mathrm{mg} /$ day and $10 \mathrm{mg} /$ day to patients with normal renal function and those with renal dysfunction, respectively [18]. There was no interaction in the safety or efficacy of rivaroxaban between the study doses regardless of the state of renal function as in the case of the ROCKET AF trial $[18,20]$.

The EXPAND Study was an investigator-initiated, multicenter registry to investigate the effectiveness and safety of rivaroxaban for the prevention of stroke/SE events in NVAF patients in routine clinical practice in Japan [21]. In the present sub-analysis, we aimed to identify the situation of rivaroxaban doses by renal function, and to reveal the effectiveness and safety of rivaroxaban in Japanese NVAF patients with renal dysfunction in the EXPAND Study.

\section{Methods}

The EXPAND Study was conducted in accordance with the principles of the Declaration of Helsinki, the Ethical Guidelines for Clinical Studies from the Japanese Ministry of Health, Labour and Welfare, and all applicable laws and regulations in Japan [21]. The protocol was reviewed and approved by the Institutional Review Boards and/or Ethics Committee at all the participating institutes. All subjects provided written informed consent before enrollment in this study. The present study is registered with Clinical trials. gov., number NCT02147444, and with the University Hospital Medical Information Network Clinical Trials Registry, number UMIN000009376.

In the present sub-analysis, we included 6806 patients whose baseline $\mathrm{CrCl}$ data were available and divided them into 2 groups by baseline $\mathrm{CrCl}$ levels; normal renal function group with $\mathrm{CrCl} \geq 50 \mathrm{~mL} / \mathrm{min}$ and renal dysfunction group with $\mathrm{CrCl}<50 \mathrm{~mL} / \mathrm{min}$. The 2 groups were further stratified by the dose of rivaroxaban $(10 \mathrm{mg} /$ day vs. $15 \mathrm{mg} /$ day). The value of $\mathrm{CrCl}$ was estimated by CockcroftGault formula as $(140-[$ age $]) \times$ (body weight $) / 72$ $\times$ (serum creatinine) $(\times 0.85$ for female $s)$ [22]. The patients treated with rivaroxaban $15 \mathrm{mg}$ in the renal dysfunction group were defined as an over-dose group and those treated with rivaroxaban $10 \mathrm{mg}$ in the normal renal function group was defined as an under-dose group. The 2 standard-dose groups were defined as the patients treated with rivaroxaban $10 \mathrm{mg}$ and $15 \mathrm{mg}$ in the renal dysfunction and the normal renal function groups, respectively.

Baseline patient characteristics were described and stratified by renal function and rivaroxaban dose. The cumulative incidences of stroke/SE, ischemic stroke, major bleeding, and non-major bleeding were evaluated and compared. Bleeding events were defined as International Society on Thrombosis and Haemostasis criteria [23]. The annual incidences of stroke/SE, ischemic stroke, all-cause death, major bleeding, and non-major bleeding were estimated based on the time to first event using the Kaplan-Meier estimate and calculated using the log-rank test by renal function and rivaroxaban dose.

Numerical data are expressed as mean \pm standard deviation (SD). Testing for significant differences was performed by a $\chi^{2}$ test, Wilcoxon rank-sum test, or Student's $t$ test. We used propensity score matching (PSM) to adjust the clinical backgrounds between patients with normal renal function and those with renal dysfunction for the following clinical variables: age, sex, type of AF, body weight, congestive heart failure, hypertension, diabetes mellitus, ischemic stroke/SE, cardiovascular disease as a myocardial infraction/angina pectoris, $\mathrm{CrCl}$ level, history of bleeding/bleeding tendency, and concomitant use of anti-platelet agents. A two-sided significance level of 5\% was employed, and all statistical analyses were conducted using SAS software (for Windows Release ver.9.2 or later versions; SAS Institute Inc.).

\section{Results}

Of the 7141 patients enrolled in the EXPAND Study, 6806 patients with $\mathrm{CrCl}$ values at baseline were analyzed in the present study. A total of 5326 patients were included in the normal renal function group $(\mathrm{CrCl} \geq 50 \mathrm{~mL} / \mathrm{min})$, and 1480 patients in the renal dysfunction group $(\mathrm{CrCl}<50 \mathrm{~mL} / \mathrm{min})$ (Table 1). In the normal renal function group, $30.2 \%$ of the patients (1609/5326 patients) received the reduced dose of rivaroxaban $10 \mathrm{mg} /$ day as an under-dose group, while in the renal dysfunction group, $7.3 \%$ of the patients $(108 / 1480$ patients) received the non-reduced dose of rivaroxaban $15 \mathrm{mg} /$ day as an over-dose group (Table 1). The number of 
Table 1 Patient characteristics by creatinine clearance

\begin{tabular}{|c|c|c|c|c|}
\hline & $(n=6806)$ & $\begin{array}{l}\text { Normal renal } \\
\text { function group } \\
(\mathrm{CrCl} \geq 50 \mathrm{~mL} / \\
\min ) \\
(n=5326)\end{array}$ & $\begin{array}{l}\text { Renal dysfunc- } \\
\text { tion group } \\
(\mathrm{CrCl}<50 \mathrm{~mL} / \\
\min ) \\
(n=1480)\end{array}$ & $P$ value ${ }^{\dagger}$ \\
\hline Sex (male), $n(\%)$ & $4605(67.7)$ & $3838(72.1)$ & $767(51.8)$ & $<0.001$ \\
\hline Age (years), mean $\pm S D$ & $71.6 \pm 9.4$ & $69.4 \pm 8.9$ & $79.8 \pm 6.1$ & $<0.001$ \\
\hline Age $\geq 75$ years, $n(\%)$ & $2819(41.4)$ & $1596(30.0)$ & $1223(82.6)$ & $<0.001$ \\
\hline Body weight $(\mathrm{kg})$, mean \pm SD & $62.7 \pm 12.5$ & $65.5 \pm 11.8$ & $52.9 \pm 9.5$ & $<0.001$ \\
\hline $\mathrm{CHADS}_{2}$ score, mean $\pm \mathrm{SD}$ & $2.1 \pm 1.3$ & $1.9 \pm 1.3$ & $2.8 \pm 1.3$ & $<0.001$ \\
\hline$<2$ points, $n(\%)$ & $2498(36.7)$ & $2279(42.8)$ & $219(14.8)$ & $<0.001$ \\
\hline 2 points, $n(\%)$ & $1990(29.2)$ & $1510(28.4)$ & $480(32.4)$ & \\
\hline$\geq 3$ points, $n(\%)$ & $2318(34.1)$ & $1537(28.9)$ & $781(52.8)$ & \\
\hline $\mathrm{CHA}_{2} \mathrm{DS}_{2}$-VASc score, mean $\pm \mathrm{SD}$ & $3.4 \pm 1.7$ & $3.1 \pm 1.6$ & $4.5 \pm 1.5$ & $<0.001$ \\
\hline HAS-BLED score, mean \pm SD & $1.4 \pm 0.9$ & $1.4 \pm 0.9$ & $1.6 \pm 0.8$ & $<0.001$ \\
\hline \multicolumn{5}{|l|}{ Rivaroxaban dosage, $n(\%)$} \\
\hline $10 \mathrm{mg} /$ day & $2981(43.8)$ & $1609(30.2)$ & $1372(92.7)$ & - \\
\hline $15 \mathrm{mg} /$ day & $3825(56.2)$ & $3717(69.8)$ & $108(7.3)$ & - \\
\hline \multicolumn{5}{|l|}{ Comorbidity and medical history, $n(\%)$} \\
\hline Congestive heart failure & $1806(26.5)$ & $1209(22.7)$ & $597(40.3)$ & $<0.001$ \\
\hline Hypertension & $4843(71.2)$ & $3743(70.3)$ & $1100(74.3)$ & 0.002 \\
\hline Diabetes mellitus & $1679(24.7)$ & $1323(24.8)$ & $356(24.1)$ & 0.535 \\
\hline Angina pectoris & $803(11.8)$ & $582(10.9)$ & $221(14.9)$ & $<0.001$ \\
\hline Dyslipidemia & $2864(42.1)$ & $2270(42.6)$ & $594(40.1)$ & 0.087 \\
\hline Stroke (ischemic/hemorrhagic) & $1459(21.4)$ & $1068(20.1)$ & $391(26.4)$ & $<0.001$ \\
\hline Ischemic stroke & $1373(20.2)$ & $1001(18.8)$ & $372(25.1)$ & $<0.001$ \\
\hline Hemorrhagic stroke & $130(1.9)$ & $98(1.8)$ & $32(2.2)$ & 0.423 \\
\hline Transient ischemic attack & $206(3.0)$ & $152(2.9)$ & $54(3.6)$ & 0.114 \\
\hline Systemic embolism & $58(0.9)$ & $43(0.8)$ & $15(1.0)$ & 0.445 \\
\hline Myocardial infarction & $285(4.2)$ & $199(3.7)$ & $86(5.8)$ & $<0.001$ \\
\hline Malignant tumor & $625(9.2)$ & $446(8.4)$ & $179(12.1)$ & $<0.001$ \\
\hline Bleeding and/or bleeding tendency & $276(4.1)$ & $218(4.1)$ & $58(3.9)$ & 0.764 \\
\hline Non-PAF (persistent/permanent), $n(\%)$ & $3783(55.6)$ & $2922(54.9)$ & $861(58.2)$ & 0.023 \\
\hline Use of concomitant anti-platelet, $n(\%)$ & $640(9.4)$ & $727(13.7)$ & $263(17.8)$ & $<0.001$ \\
\hline
\end{tabular}

$\mathrm{CrCl}$ creatinine clearance, $\mathrm{PAF}$ paroxysmal atrial fibrillation, $S D$ standard deviation

${ }^{\dagger} \mathrm{CrCl} \geq 50 \mathrm{~mL} / \mathrm{min}$ vs. $\mathrm{CrCl}<50 \mathrm{~mL} / \mathrm{min}$ patients in the standard-dose groups was $92.7 \%$ of the renal dysfunction (1372/1480 patients) and $69.8 \%$ of the normal renal function $(3717 / 5326$ patients).

\section{Baseline patient characteristics by renal function}

Patient characteristics in the normal renal function and renal dysfunction groups are shown in Table 1 . There were significant differences in most factors at baseline between the 2 groups.

Patient characteristics by $\mathrm{CrCl}$ and rivaroxaban dose at baseline are shown in Table 2. In unmatched cohort, in the renal dysfunction group, there was no difference in clinical characteristics except for mean age and proportion of age $\geq 75$ years between the standard-dose and over-dose group. In contrast, in the normal renal function group, there were significant differences in the majority of factors between the standard-dose and the under-dose group, except for diabetes mellitus, dyslipidemia, stroke including ischemic and hemorrhagic, SE, and non-paroxysmal AF.

In the PSM analysis, patient characteristics were well balanced between rivaroxaban $10 \mathrm{mg} /$ day and $15 \mathrm{mg} /$ day groups in both renal function groups, and those results are shown as propensity score matched cohort in Table 2.

\section{Effectiveness and safety endpoints}

The effectiveness and safety outcomes by $\mathrm{CrCl}$ are shown in Table 3. The incidence of stroke/SE was significantly higher in the renal dysfunction group than in the normal renal function 


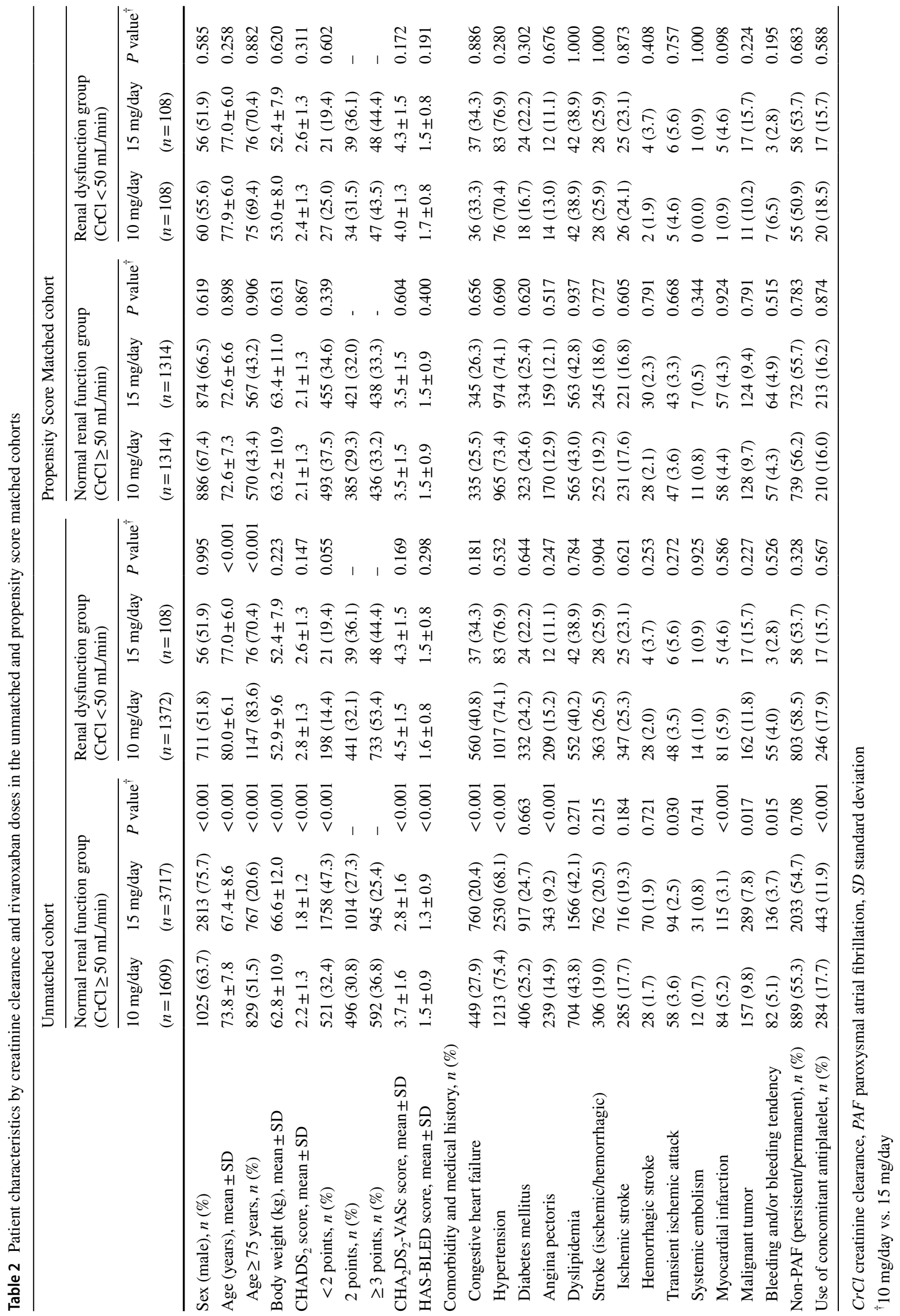


Table 3 Effectiveness and safety endpoints by creatinine clearance

\begin{tabular}{llllr}
\hline & Total & $\begin{array}{l}\text { Normal renal func- } \\
\text { tion group } \\
(\mathrm{CrCl} \geq 50 \mathrm{~mL} / \mathrm{min}) \\
(n=5326)\end{array}$ & $\begin{array}{l}\text { Renal dysfunction } \\
\text { group } \\
(\mathrm{CrCl}<50 \mathrm{~mL} / \mathrm{min}) \\
(n=1480)\end{array}$ & $P^{\text {value }^{\dagger}}$ \\
\hline Effectiveness endpoint & & & $52(1.47)$ & $<0.001$ \\
Stroke/Systemic embolism & $164(0.98)$ & $112(0.85)$ & $40(1.13)$ & 0.001 \\
Ischemic stroke & $121(0.72)$ & $81(0.61)$ & $134(3.79)$ & $<0.001$ \\
All-cause death & $270(1.61)$ & $136(1.03)$ & $68(1.92)$ & $<0.001$ \\
Safety endpoint & & & $182(5.15)$ & 0.474 \\
Major bleeding & $206(1.23)$ & $138(1.05)$ & & \\
Non-major bleeding & $815(4.87)$ & $633(4.80)$ & & \\
\hline
\end{tabular}

Figures are number of event (\%/year)

$\mathrm{CrCl}$ creatinine clearance

${ }^{\dagger} \mathrm{CrCl} \geq 50 \mathrm{~mL} / \mathrm{min}$ vs. $\mathrm{CrCl}<50 \mathrm{~mL} / \mathrm{min}$ group $(1.47 \% /$ year vs. $0.85 \% /$ year, $P<0.001)$, and this was also the case for the incidence of ischemic stroke $(1.13 \% / y e a r$ vs. $0.61 \% /$ year, $P=0.001)$ and all-cause death $(3.79 \% /$ year vs. $1.03 \% /$ year, $\mathrm{P}<0.001$ ). Regarding the safety, the incidence of major bleeding was significantly higher in the renal dysfunction group than in the normal renal function group (1.92\%/ year vs. $1.05 \% /$ year, $P<0.001$ ), while there was no significant difference in the incidence of non-major bleeding (5.15\%/year vs. $4.80 \%$ year, $P=0.474$ ) between the 2 groups.

The effectiveness and safety outcomes according to $\mathrm{CrCl}$ and rivaroxaban doses in the unmatched cohort are shown in Fig. 1 and Table 4. In the renal dysfunction group, there was significant difference in the incidence of major bleeding event between standard-dose and over-dose groups (1.80\%/ year vs. $3.53 \% /$ year, $P=0.046$ ). In the normal renal function group, there was no significant difference in the incidence of major bleeding event between under-dose and standard-dose groups $(1.13 \%$ year vs. $1.01 \% /$ year, $\mathrm{P}=0.506)$, whereas significant difference in the incidence of all-cause death was noted between the 2 groups (1.67\%/year vs. $0.75 \% / y e a r, P<0.001)$.

The effectiveness and safety endpoints according to $\mathrm{CrCl}$ and rivaroxaban doses in the propensity score matched cohort are shown in Fig. 2 and Table 4. In the renal dysfunction group, although not significantly different, the incidence rates of all endpoints tended to be higher in the over-dose than in the standard-dose groups. In contrast, in the normal renal function group, there was a significant difference in non-major bleeding event between the under-dose and the standard-dose groups $(4.28 \% /$ year vs. $5.62 \% /$ year, $P=0.010)$.

\section{Discussion}

The present study was conducted to reveal the actual conditions of use and the effectiveness and safety of rivaroxaban in Japanese NVAF patients with a special reference to renal function in the EXPAND Study. In the normal renal function group, $30 \%$ received under-dose, and in the renal dysfunction group, $7 \%$ received over-dose of rivaroxaban. In the renal dysfunction group, the incidence of stroke/SE was higher than in the normal renal function group and the incidences of ischemic stroke and all-cause death were also higher in the former than in the latter, which was also the case for major bleeding.

The incidences of stroke and major bleeding have been reported to elevate due to renal dysfunction even without anticoagulation [6-13]. Although warfarin has been reported to decrease the risk in patients at risk of thromboembolism $[11,24]$, this point remains to be adequately evaluated for DOACs. For the clinical issue of renal dysfunction, poor control of time in therapeutic range is known to be a poor prognostic factor for the use of warfarin [25]. DOACs could solve this issue if adherence is maintained. However, not only the risk of stroke/SE but also the risk of bleeding is anticipated to increase in patients with renal dysfunction. In a study using a database in the UK with PSM analysis [26], anticoagulant therapy was found to be associated with increased rate of ischemic stroke and hemorrhage but with lower all-cause mortality in elderly patients aged $\geq 65$ years with reduced estimated glomerular filtration rate [26]. In this UK study, $71.7 \%$ of the patients were on warfarin, an approximately one-quarter of all the patients used DOACs, of whom $12.7 \%$ were on rivaroxaban [26].

For the risk assessment in NVAF patients, the $\mathrm{CHADS}_{2}$ and $\mathrm{CHA}_{2} \mathrm{DS}_{2}$-VASc scores are widely used, and important risk of anticoagulation is bleeding. The present results also support the importance of adjustment of dose of rivaroxaban 
Fig. 1 Kaplan-Meier estimates for the primary effectiveness endpoints (a) and safety endpoints (b) by creatinine clearance and rivaroxaban doses in the unmatched cohort. $\mathrm{CrCl}$; creatinine clearance

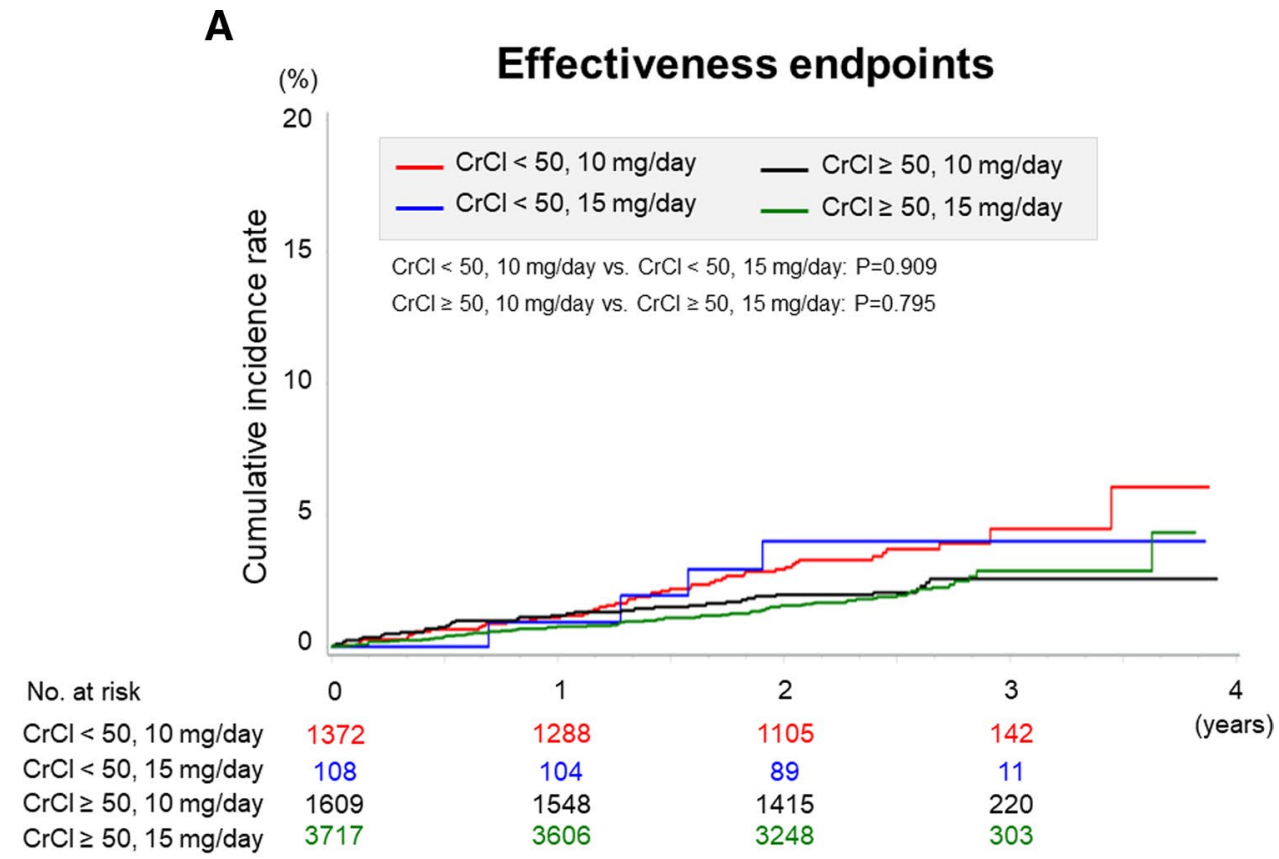

B

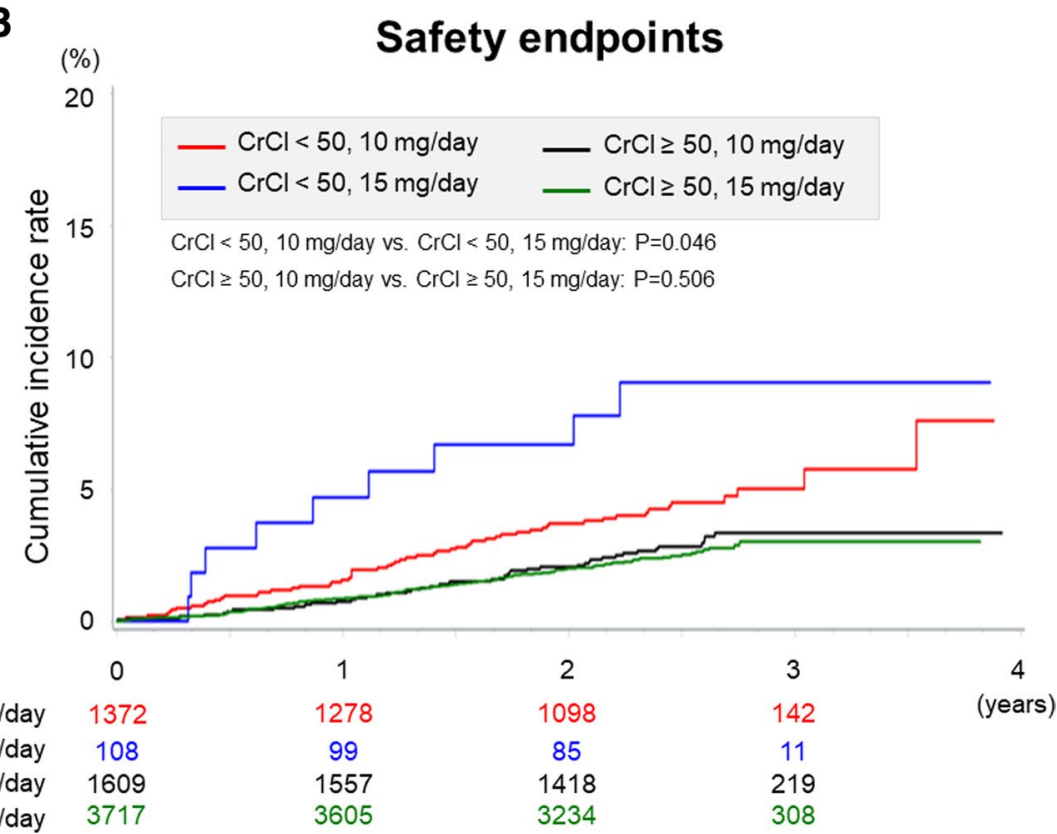

based on renal dysfunction as evaluated by $\mathrm{CrCl}$ values. The ORBIT bleeding score proposes an evaluation method adding renal dysfunction (hazard ratio 1.44) [27]. In the current era with DOACs, it is important to add renal function for evaluation of bleeding risk. For those with $\mathrm{CrCl}<50 \mathrm{~mL} /$ min, as demonstrated in the present study, the bleeding risk with rivaroxaban should be adequately assessed, and the clinical course should also be carefully monitored.

It is recommended to decrease the dose of rivaroxaban for patients with renal dysfunction, although it has been reported that in real-world clinical practice, doses are often chosen that are not as described in the package insert, considering the individual patient's background $[15,16,28]$. In the present study, there were a small number of patients receiving over-dose of rivaroxaban, and its influence was compared with those receiving standard-dose in the unmatched and the propensity score matched cohorts. The results showed that the incidence of stroke/SE in the renal dysfunction group did not differ between standard-dose and over-dose in the unmatched cohorts, whereas the incidence of major bleeding increased in 


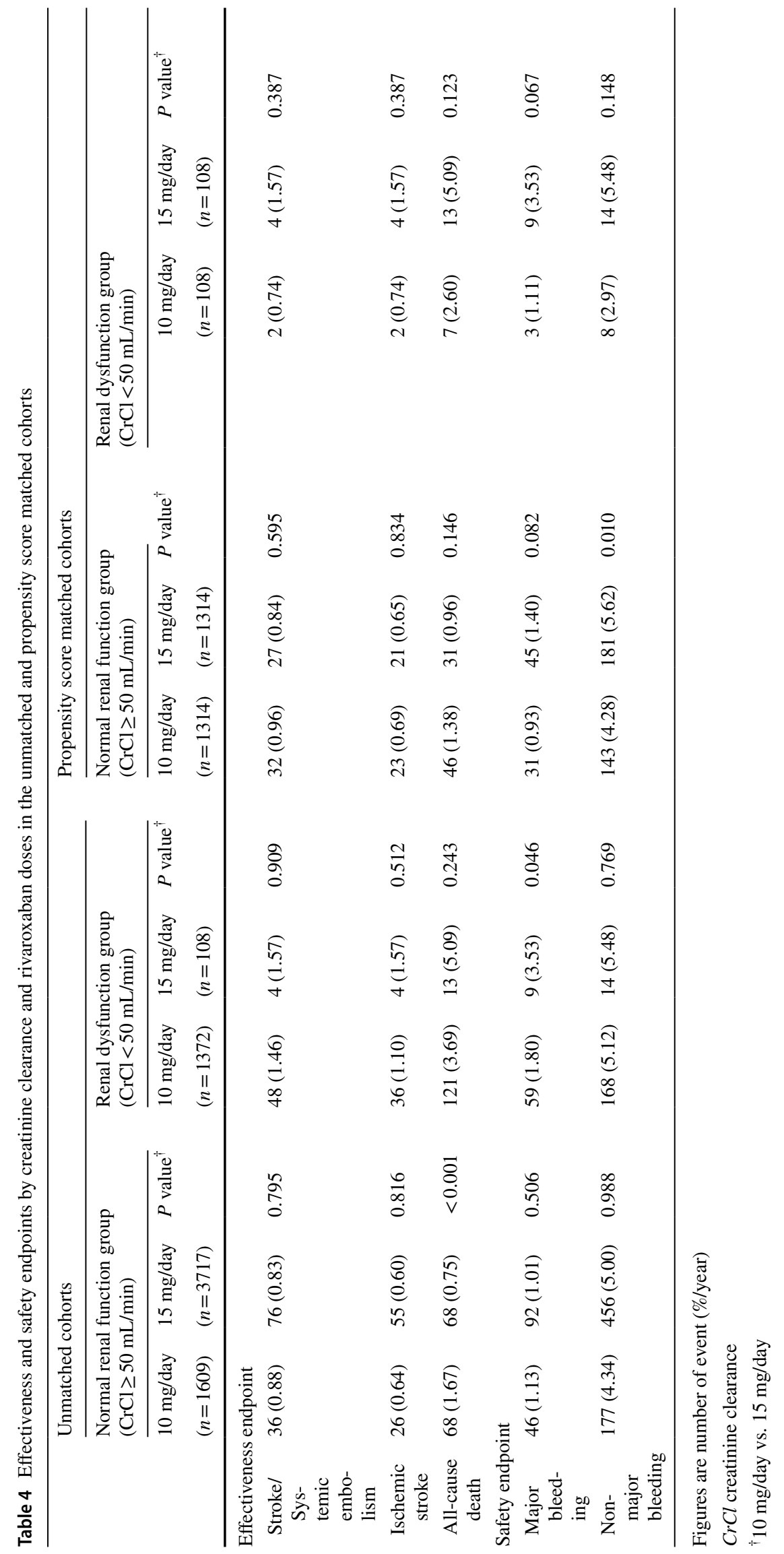


Fig. 2 Kaplan-Meier estimates for the primary effectiveness endpoints (a) and safety endpoints (b) by creatinine clearance and rivaroxaban doses in the propensity score matched cohort. $\mathrm{CrCl}$; creatinine clearance

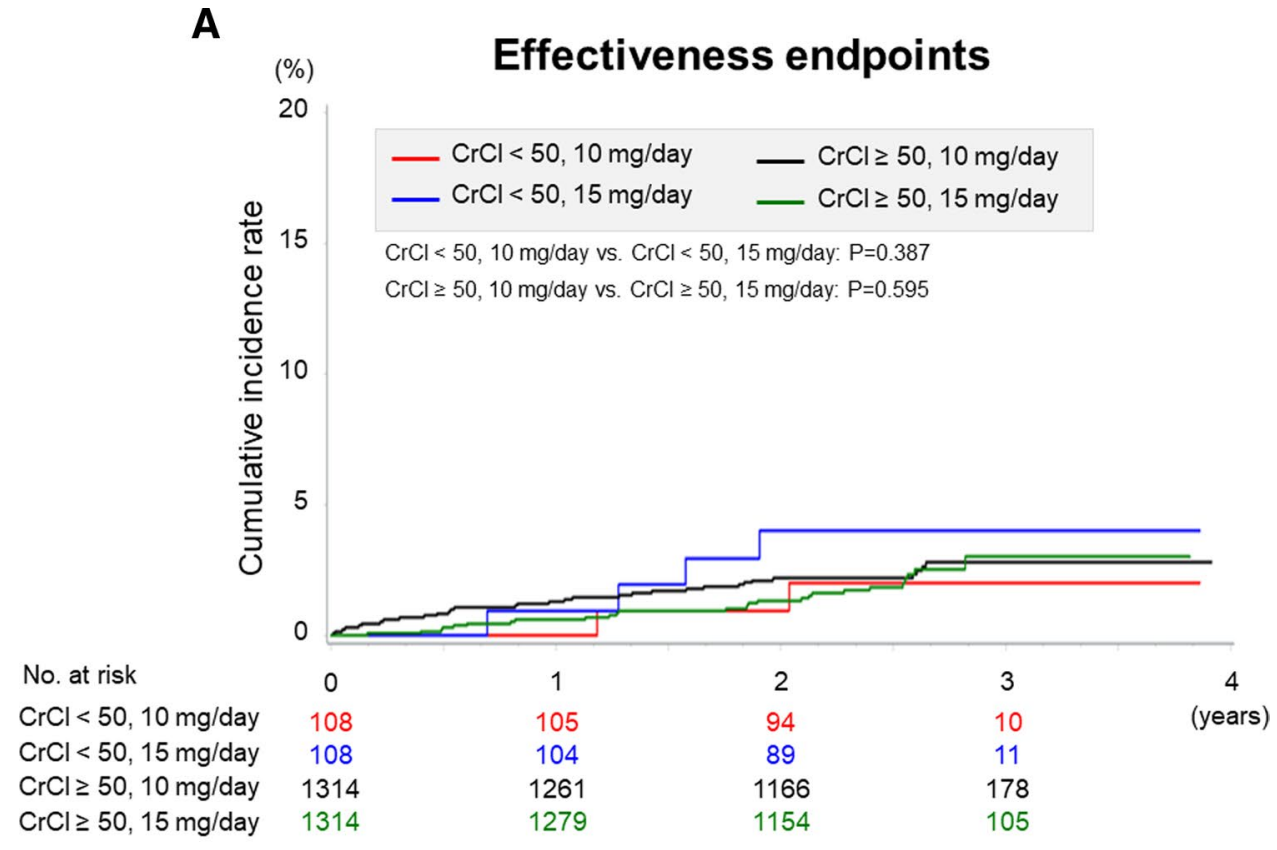

B

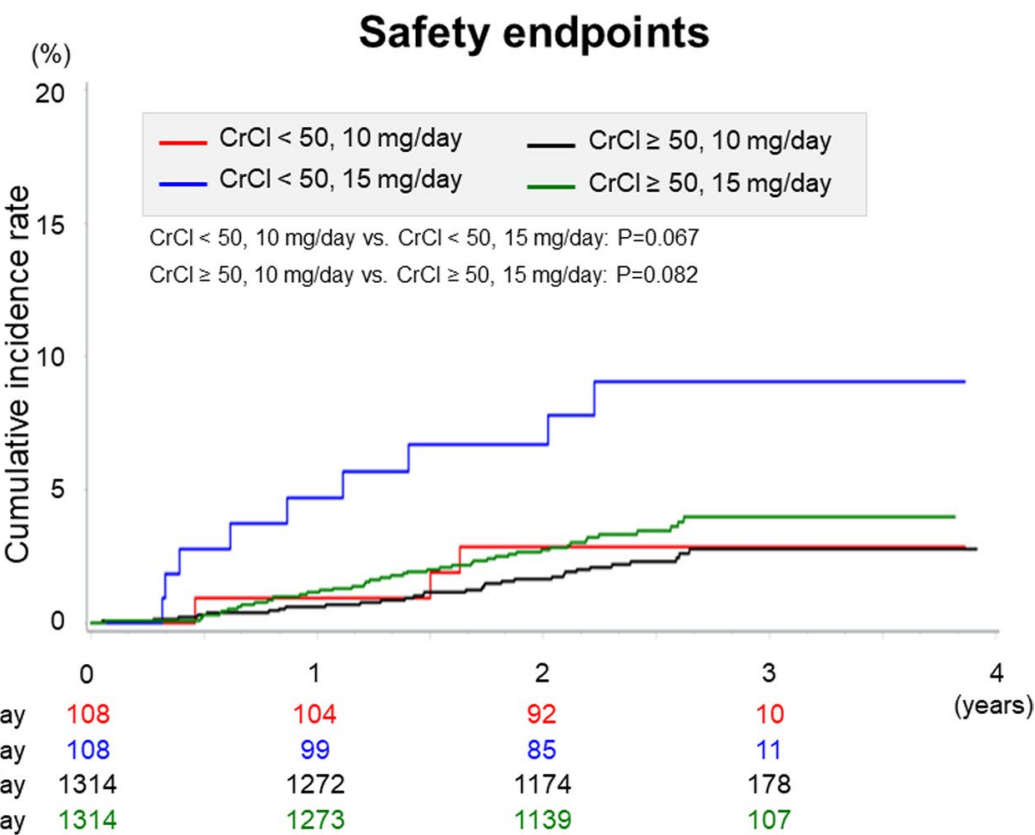

this group with over-dose in the unmatched cohort. In contrast, interestingly, the incidence of stroke/SE tended to be higher and that of major bleeding tended to be lower in the underdose group as compared with the standard-dose group in the propensity score matched cohort. The XAPASS showed that the under-dosing was associated with a decreased incidence rate of any bleeding, but not that of major bleeding [29]. In the normal renal function group, there were significant differences between patients with standard-dose and those with underdose in characteristics at baseline, $\mathrm{CHADS}_{2}, \mathrm{CHA}_{2} \mathrm{DS}_{2}-\mathrm{VASc}$, and HAS-BLED scores. The patients with low $\mathrm{CHADS}_{2}$ score as a less than 2 points were included approximately $32 \%$ and $47 \%$ in the under-dose and standard-dose groups, respectively. In our previous report of this EXPAND study, we showed that patients with a higher $\mathrm{CHADS}_{2}$ score had a higher incidence rate of stroke/SE and major bleeding events [21]. However, in the results of the present sub-analysis of unmatched cohort, there was no change in the incidence rates except for all-cause death between the under-dose and standard-dose groups despite the fact that mean $\mathrm{CHADS}_{2}$ score was higher in the 
under-dose than in the standard-dose groups. Physicians are reducing dose of anticoagulants for elderly AF patients based on the risk, such as frailty, polypharmacy, and dementia or cognitive impairment [30-32], which impossible to express by the $\mathrm{CHADS}_{2}$ score [33]. Under dosing of anticoagulant for elderly patients may be superior to standard dosing [34], and the results of this study seem to support those findings.

As for the reason for the higher mortality in the underdose group may be due to the fact that the under-dose group included more elderly patients as compared with the standard-dose group. On the other hand, the GARFIELDAF study showed that under-dosing of DOACs was associated with an increased risk of death, and under-dosing was associated with higher risk of death compared with standard dosing (hazard ratio $1.25,95 \%$ CI $1.04-1.50$ ) [35]. In this registry, the patients' background, such as age, and $\mathrm{CHA}_{2} \mathrm{DS}_{2}$-VASc score and the incidence of stroke and bleeding, was similar to those of the EXPAND Study. However, this registry included a variety of races, and it is necessary to consider racial differences and Japan-specific dose of DOACs.

With regard to the incidence of major bleeding, the propensity score matched cohort in the normal renal function group showed a numerically higher incidence in the rivaroxaban standard-dose than in the under-dose groups, with no difference in ischemic events. These results indicate that the dose should be decreased in accordance with the criteria for dose reduction for patients with renal dysfunction (10 mg for patients with $\mathrm{CrCl}<50 \mathrm{~mL} / \mathrm{min}$ ) and suggest that some NVAF patients with normal renal function may do better with under-dose of rivaroxaban considering the balance between the risks of bleeding and ischemic events.

\section{Study limitations}

We have previously mentioned several limitations in the EXPAND Study [21, 36, 37]. Furthermore, in the present sub-analysis, the following limitations should be considered. First, although patients were classified by $\mathrm{CrCl}$ values and the dose of rivaroxaban at baseline, $\mathrm{CrCl}$ values and the dose of rivaroxaban at the onset of events were not available. Second, since the EXPAND Study was an observational study, the dose of rivaroxaban was chosen at the discretion of physicians, and no assessment of adherence was performed. Third, the analysis of this report used propensity score matching, and the number of patients after the matching was decreased by $85 \%$ in the renal dysfunction group and by $51 \%$ in the normal renal function groups. This could have affected the results of the present sub-analysis. Finally, a relatively small number of endpoints might have failed to detect a clinically important difference in safety.

\section{Conclusion}

In the present sub-analysis of the EXPAND Study, we were able to demonstrate the incidences of effectiveness and safety events in NVAF patients according to renal function and rivaroxaban doses. The present results support the current recommendation that the dose of rivaroxaban should be reduced to $10 \mathrm{mg} /$ day for patients with renal dysfunction with $\mathrm{CrCl}<50 \mathrm{~mL} / \mathrm{min}$. On the other hand, rivaroxaban dose should be reduced depending on renal function, considering the balance between risks of bleeding and ischemia. However, since there was no enough evidence for using under-dose in patients with normal renal function, further clinical data are needed for better use of rivaroxaban in those patients.

Author contributions HS takes responsibility for all aspects of the reliability and freedom from bias of the data presented and their discussed interpretation.

Funding The EXPAND Study is an investigator-initiated clinical study based on a collaborative contract with Tohoku University Hospital and Bayer Yakuhin Ltd. The company had no role in the study design, study conduct, data collection, data analysis, or preparation and submission of manuscript.

\section{Declarations}

Conflict of interest H.A. has received personal fee from Daiichi Sankyo, outside the submitted work. S.U. has received personal fees from Bayer, Bristol-Myers Squibb, Boehringer Ingelheim, Daiichi Sankyo, Sanofi, Dainippon Sumitomo, Otsuka, Takeda, Astellas, AstraZeneka, Sanwa Kagaku, Shionogi, Mitsubishi Tanabe, and Pfizer, outside the submitted work. H.I. has received personal fees from Bayer Healthcare, Boehringer Ingelheim, Daiichi-Sankyo, and Bristol-Myers Squibb, outside the submitted work. T.K. has received grants and personal fees from Daiichi Sankyo, Bayer Yakuhin, Pfizer, Chugai, Boehringer Ingelheim, Mitsubishi Tanabe, Shionogi, Astellas, and MSD; personal fees from Bristol-Myers Squibb, Sanofi, and AstraZeneca; and grants from Takeda, Kissei, Kyowa Hakko Kirin, EA Pharma, Asahi Kasei Medical, Otsuka, Torii, Eisai, Ono, Zeria, and Dainippon Sumitomo, outside the submitted work. T.Y. has received grants and personal fees from Bayer, Daiichi Sankyo, Bristol-Myers Squibb, and Mitsubishi Tanabe; and personal fees from Pfizer, Eisai, Ono Pharmaceutical, Toa Eiyo, and Nippon Boehringer, outside the submitted work. W.S. has received grants and personal fees from Bayer, Daiichi Sankyo, Nippon Boehringer, Bristol-Myers Squibb, Pfizer, Eisai, Ono Pharmaceutical, and Mitsubishi Tanabe, outside the submitted work. T.I reports grants and personal fees from Daiichi-Sankyo, personal fees from Bayer, grants and personal fees from Bristol-Myers Squibb, personal fees from Pfizer, grants from Boehringer Ingelheim, outside the submitted work. M.K. has received personal fees from Tohoku University, during the conduct of the study; and personal fees from Bayer, outside the submitted work. K.K. has received grants from Bayer Yakuhin, Ltd., Daiichi-Sankyo Co., Ltd.; and honoraria from Bayer Yakuhin, Ltd, and Daiichi-Sankyo Co., Ltd., outside the submitted work. K.F. has received personal fees from Bayer, outside the submitted work. H.O. has received personal fees from Daiichi-Sankyo and Bayer, outside the submitted work. H.S. has received personal fees from Bayer, and Daiichi Sankyo, outside the submitted work. 
Open Access This article is licensed under a Creative Commons Attribution 4.0 International License, which permits use, sharing, adaptation, distribution and reproduction in any medium or format, as long as you give appropriate credit to the original author(s) and the source, provide a link to the Creative Commons licence, and indicate if changes were made. The images or other third party material in this article are included in the article's Creative Commons licence, unless indicated otherwise in a credit line to the material. If material is not included in the article's Creative Commons licence and your intended use is not permitted by statutory regulation or exceeds the permitted use, you will need to obtain permission directly from the copyright holder. To view a copy of this licence, visit http://creativecommons.org/licenses/by/4.0/.

\section{References}

1. Feinberg WM, Blackshear JL, Laupacis A, Kronmal R, Hart RG (1995) Prevalence, age distribution, and gender of patients with atrial fibrillation. Anal Implic Arch Intern Med 155:469-473

2. Wolf PA, Abbott RD, Kannel WB (1991) Atrial fibrillation as an independent risk factor for stroke: the Framingham Study. Stroke 22:983-988

3. Inoue H, Fujiki A, Origasa H, Ogawa S, Okumura K, Kubota I, Aizawa Y, Yamashita T, Atarashi H, Horie M, Ohe T, Doi Y, Shimizu A, Chishaki A, Saikawa T, Yano K, Kitabatake A, Mitamura H, Kodama I, Kamakura S (2009) Prevalence of atrial fibrillation in the general population of Japan: an analysis based on periodic health examination. Int J Cardiol 137:102-107

4. JCS Joint Working Group (2014) Guidelines for pharmacotherapy of atrial fibrillation (JCS 2013). Circ J 78:1997-2021

5. Steffel J, Verhamme P, Potpara TS, Albaladejo P, Antz M, Desteghe L, Haeusler KG, Oldgren J, Reinecke H, RoldanSchilling V, Rowell N, Sinnaeve P, Collins R, Camm AJ, Heidbuchel H, Group ESCSD (2018) The 2018 European heart rhythm association practical guide on the use of non-vitamin $\mathrm{K}$ antagonist oral anticoagulants in patients with atrial fibrillation. Eur Heart J 39:1330-1393

6. Japanese Society of Nephrology (2007) Special issue: clinical practice guidebook for diagnosis and treatment of CKD. Nihon Jinzo Gakkai Shi 49:757-861 ((in Japanese))

7. Toyoda K, Ninomiya T (2014) Stroke and cerebrovascular diseases in patients with chronic kidney disease. Lancet Neurol 13:823-833

8. Nakagawa K, Hirai T, Takashima S, Fukuda N, Ohara K, Sasahara E, Taguchi Y, Dougu N, Nozawa T, Tanaka K, Inoue H (2011) Chronic kidney disease and CHADS(2) score independently predict cardiovascular events and mortality in patients with nonvalvular atrial fibrillation. Am J Cardiol 107:912-916

9. Nakayama M, Metoki H, Terawaki H, Ohkubo T, Kikuya M, Sato T, Nakayama K, Asayama K, Inoue R, Hashimoto J, Totsune K, Hoshi H, Ito S, Imai Y (2007) Kidney dysfunction as a risk factor for first symptomatic stroke events in a general Japanese population-the Ohasama study. Nephrol Dial Transplant 22:1910-1915

10. Go AS, Fang MC, Udaltsova N, Chang Y, Pomernacki NK, Borowsky L, Singer DE, AS Investigators (2009) Impact of proteinuria and glomerular filtration rate on risk of thromboembolism in atrial fibrillation: the anticoagulation and risk factors in atrial fibrillation (ATRIA) study. Circulation 119:1363-1369

11. Olesen JB, Lip GY, Kamper AL, Hommel K, Kober L, Lane DA, Lindhardsen J, Gislason GH, Torp-Pedersen C (2012) Stroke and bleeding in atrial fibrillation with chronic kidney disease. N Engl J Med 367:625-635

12. Abumuaileq RR, Abu-Assi E, Lopez-Lopez A, Raposeiras-Roubin S, Rodriguez-Manero M, Martinez-Sande L, Garcia-Seara
FJ, Fernandez-Lopez XA, Gonzalez-Juanatey JR (2015) Renal function assessment in atrial fibrillation: usefulness of chronic kidney disease epidemiology collaboration vs re-expressed 4 variable modification of diet in renal disease. World J Cardiol 7:685-694

13. Lau YC, Proietti M, Guiducci E, Blann AD, Lip GYH (2016) Atrial fibrillation and thromboembolism in patients with chronic kidney disease. J Am Coll Cardiol 68:1452-1464

14. Dahal K, Kunwar S, Rijal J, Schulman P, Lee J (2016) Stroke, major bleeding, and mortality outcomes in warfarin users with atrial fibrillation and chronic kidney disease: a meta-analysis of observational studies. Chest 149:951-959

15. Abe M, Ogawa H, Ishii M, Masunaga N, Esato M, Chun YH, Tsuji H, Wada H, Hasegawa K, Lip GY, Akao M (2017) Relation of stroke and major bleeding to creatinine clearance in patients with atrial Ffbrillation (from the Fushimi AF registry). Am J Cardiol 119:1229-1237

16. Kodani E, Atarashi H, Inoue H, Okumura $\mathrm{K}$, Yamashita $\mathrm{T}$, Origasa H, Investigators JRR (2018) Impact of creatinine clearance on outcomes in patients with non-valvular atrial fibrillation: a subanalysis of the J-RHYTHM registry. Eur Heart J Qual Care Clin Outcomes 4:59-68

17. Patel MR, Mahaffey KW, Garg J, Pan G, Singer DE, Hacke W, Breithardt G, Halperin JL, Hankey GJ, Piccini JP, Becker RC, Nessel CC, Paolini JF, Berkowitz SD, Fox KA, Califf RM, Investigators RA (2011) Rivaroxaban versus warfarin in nonvalvular atrial fibrillation. N Engl J Med 365:883-891

18. Hori M, Matsumoto M, Tanahashi N, Momomura S, Uchiyama S, Goto S, Izumi T, Koretsune Y, Kajikawa M, Kato M, Ueda H, Iwamoto K, Tajiri M, investigators JRAs (2012) Rivaroxaban vs. warfarin in Japanese patients with atrial fibrillation - the J-ROCKET AF study. Circ J 76:2104-2111

19. Fox KA, Piccini JP, Wojdyla D, Becker RC, Halperin JL, Nessel CC, Paolini JF, Hankey GJ, Mahaffey KW, Patel MR, Singer DE, Califf RM (2011) Prevention of stroke and systemic embolism with rivaroxaban compared with warfarin in patients with non-valvular atrial fibrillation and moderate renal impairment. Eur Heart J 32:2387-2394

20. Hori M, Matsumoto M, Tanahashi N, Momomura S, Uchiyama S, Goto S, Izumi T, Koretsune Y, Kajikawa M, Kato M, Ueda H, Iwamoto K, Tajiri M, Investigators JRAs (2013) Safety and efficacy of adjusted dose of rivaroxaban in Japanese patients with non-valvular atrial fibrillation: subanalysis of J-ROCKET AF for patients with moderate renal impairment. Circ J 77:632-638

21. Shimokawa H, Yamashita T, Uchiyama S, Kitazono T, Shimizu W, Ikeda T, Kamouchi M, Kaikita K, Fukuda K, Origasa H, Sakuma I, Saku K, Okumura Y, Nakamura Y, Morimoto H, Matsumoto N, Tsuchida A, Ako J, Sugishita N, Shimizu S, Atarashi H, Inoue H (2018) The EXPAND study: efficacy and safety of rivaroxaban in Japanese patients with non-valvular atrial fibrillation. Int J Cardiol 258:126-132

22. Cockcroft DW, Gault MH (1976) Prediction of creatinine clearance from serum creatinine. Nephron 16:31-41

23. Schulman S, Kearon C, Subcommittee on Control of Anticoagulation of the Scientific and Standardization Committee of the International Society on Thrombosis and Haemostasis (2005) Definition of major bleeding in clinical investigations of antihemostatic medicinal products in non-surgical patients. J Thromb Haemost 3:692-694

24. Jun M, James MT, Ma Z, Zhang J, Tonelli M, McAlister FA, Manns BJ, Ravani P, Quinn RR, Wiebe N, Perkovic V, Wilton SB, Winkelmayer WC, Hemmelgarn BR, Alberta Kidney Disease N (2017) Warfarin initiation, atrial fibrillation, and kidney function: comparative effectiveness and safety of warfarin in older adults with newly diagnosed atrial fibrillation. Am J Kidney Dis 69:734-743 
25. Inoue H, Kodani E, Atarashi H, Okumura K, Yamashita T, Origasa H, Investigators JRR (2018) Renal dysfunction affects anticoagulation control with warfarin and outcomes in Japanese elderly patients with non-valvular atrial fibrillation. Circ J 82:2277-2283

26. Kumar S, de Lusignan S, McGovern A, Correa A, Hriskova M, Gatenby P, Jones S, Goldsmith D, Camm AJ (2018) Ischaemic stroke, haemorrhage, and mortality in older patients with chronic kidney disease newly started on anticoagulation for atrial fibrillation: a population based study from UK primary care. BMJ 360:k342

27. O'Brien EC, Simon DN, Thomas LE, Hylek EM, Gersh BJ, Ansell JE, Kowey PR, Mahaffey KW, Chang P, Fonarow GC, Pencina MJ, Piccini JP, Peterson ED (2015) The ORBIT bleeding score: a simple bedside score to assess bleeding risk in atrial fibrillation. Eur Heart J 36:3258-3264

28. Murata N, Okumura Y, Yokoyama K, Matsumoto N, Tachibana E, Kuronuma K, Oiwa K, Matsumoto M, Kojima T, Hanada S, Nomoto K, Arima K, Takahashi F, Kotani T, Ikeya Y, Fukushima S, Itoh S, Kondo K, Chiku M, Ohno Y, Onikura M, Hirayama A, Investigators SAR(??) (2019) Clinical outcomes of off-label dosing of direct oral anticoagulant therapy among Japanese patients with atrial fibrillation identified from the SAKURA AF Registry. Circ J 83:727-735

29. Ikeda T, Ogawa S, Kitazono T, Nakagawara J, Minematsu K, Miyamoto S, Murakawa Y, Iwashiro S, Kidani Y, Okayama Y, Sunaya T, Sato S, Yamanaka S (2019) Outcomes associated with under-dosing of rivaroxaban for management of non-valvular atrial fibrillation in real-world Japanese clinical settings. J Thromb Thrombolysis 48:653-660

30. Perera V, Bajorek BV, Matthews S, Hilmer SN (2009) The impact of frailty on the utilisation of antithrombotic therapy in older patients with atrial fibrillation. Age Ageing 38:156-162

31. Bahri O, Roca F, Lechani T, Druesne L, Jouanny P, Serot JM, Boulanger E, Puisieux F, Chassagne P (2015) Underuse of oral anticoagulation for individuals with atrial fibrillation in a nursing home setting in France: comparisons of resident characteristics and physician attitude. J Am Geriatr Soc 63:71-76
32. Kato ET, Goto S, Giugliano RP (2019) Overview of oral antithrombotic treatment in elderly patients with atrial fibrillation. Ageing Res Rev 49:115-124

33. Gage BF, Waterman AD, Shannon W, Boechler M, Rich MW, Radford MJ (2001) Validation of clinical classification schemes for predicting stroke: results from the national registry of atrial fibrillation. JAMA 285:2864-2870

34. Okumura K, Akao M, Yoshida T, Kawata M, Okazaki O, Akashi S, Eshima K, Tanizawa K, Fukuzawa M, Hayashi T, Akishita M, Lip GYH, Yamashita T; ELDERCARE-AF Committees and Investigators (2020) Low-dose edoxaban in very elderly patients with atrial fibrillation. N Engl J Med 383:1735-1745

35. Camm AJ, Cools F, Virdone S, Bassand JP, Fitzmaurice DA, Arthur Fox KA, Goldhaber SZ, Goto S, Haas S, Mantovani LG, Kayani G, Grierson Turpie AG, Antoon Verheugt FW, Kakkar AK, GARFIELD-AF Investigators (2020) Mortality in patients with atrial fibrillation receiving nonrecommended doses of direct oral anticoagulants. J Am Coll Cardiol 76:1425-1436

36. Ikeda T, Atarashi H, Inoue H, Uchiyama S, Kitazono T, Yamashita T, Shimizu W, Kamouchi M, Kaikita K, Fukuda K, Origasa H, Sakuma I, Saku K, Okumura Y, Nakamura Y, Morimoto H, Matsumoto N, Tsuchida A, Ako J, Sugishita N, Shimizu S, Shimokawa H (2016) Study design and baseline characteristics of the EXPAND Study: Evaluation of effectiveness and safety of Xa inhibitor, rivaroxaban for the prevention of stroke and systemic embolism in a nationwide cohort of Japanese patients diagnosed as non-valvular atrial fibrillation. Tohoku J Exp Med 240:259-268

37. Uchiyama S, Atarashi $\mathrm{H}$, Inoue $\mathrm{H}$, Kitazono $\mathrm{T}$, Yamashita $\mathrm{T}$, Shimizu W, Ikeda T, Kamouchi M, Kaikita K, Fukuda K, Origasa H, Shimokawa H (2019) Primary and secondary prevention of stroke and systemic embolism with rivaroxaban in patients with non-valvular atrial fibrillation: sub-analysis of the EXPAND Study. Heart Vessels 34:141-150

Publisher's Note Springer Nature remains neutral with regard to jurisdictional claims in published maps and institutional affiliations.

\section{Authors and Affiliations}

\section{Hirotsugu Atarashi ${ }^{1} \cdot$ Shinichiro Uchiyama ${ }^{2} \cdot$ Hiroshi Inoue $^{3} \cdot$ Takanari Kitazono $^{4}$ - Takeshi Yamashita ${ }^{5}$. Wataru Shimizu ${ }^{6} \cdot$ Takanori Ikeda $^{7} \cdot$ Masahiro Kamouchi $^{8} \cdot$ Koichi Kaikita $^{9} \cdot \mathrm{Koji} \mathrm{Fukuda}^{10} \cdot$ Hideki Origasa $^{11}$. Hiroaki Shimokawa ${ }^{12,13}$ (1)}

1 Minamihachioji Hospital, Koyasu-cho 3-18-12, Hachioji, Tokyo 192-0904, Japan

2 Clinical Research Center for Medicine, International University of Health and Welfare, Akasaka 8-5-35, Minato-ku, Tokyo 107-0052, Japan

3 Saiseikai Toyama Hospital, Kusunoki 33-1, Toyama 931-8533, Japan

4 Department of Medicine and Clinical Science, Graduate School of Medical Sciences, Kyushu University, Maidashi 3-1-1, Higashi-ku, Fukuoka 812-8582, Japan

5 Cardiovascular Institute Hospital, Nishiazabu 3-2-19, Minato-Ku, Tokyo 106-0031, Japan

6 Department of Cardiovascular Medicine, Graduate School of Medicine, Nippon Medical School, Sendagi 1-1-5, Bunkyo-ku, Tokyo 113-8602, Japan

7 Department of Cardiovascular Medicine, Faculty of Medicine, Toho University, Omorinishi 5-21-16, Ota-ku, Tokyo 143-8540, Japan
8 Department of Health Care Administration and Management, Center for Cohort Study, Kyushu University Graduate School of Medical Sciences, Maidashi 3-1-1, Higashi-ku, Fukuoka 812-8582, Japan

9 Department of Cardiovascular Medicine, Graduate School of Medical Sciences, Kumamoto University, 2-39-1, Kurokami Chuo-ku, Kumamoto 860-8555, Japan

10 Division of Heart Rhythm, International University of Health and Welfare Hospital, Iguchi 537-3, Nasushiobara, Japan

11 Division of Biostatistics and Clinical Epidemiology, University of Toyama Graduate School of Medicine, Sugitani 2630, Toyama 930-0194, Japan

12 Department of Cardiovascular Medicine, Tohoku University Graduate School of Medicine, Seiryomachi 1-1, Aoba-ku, Sendai 980-8574, Japan

13 International University of Health and Welfare, Kozunomori 4-3, Narita 286-8686, Japan 